\title{
Analytical miniaturization and nanotechnologies
}

\author{
Merkoçi, Arben; Kutter, Jörg Peter
}

Published in:

Lab on a Chip

Link to article, DOI:

10.1039/c2lc90040h

Publication date:

2012

Document Version

Publisher's PDF, also known as Version of record

Link back to DTU Orbit

Citation (APA):

Merkoçi, A. (Ed.), \& Kutter, J. P. (2012). Analytical miniaturization and nanotechnologies. Lab on a Chip, 12(11), 1915-1916. https://doi.org/10.1039/c2lc90040h

\section{General rights}

Copyright and moral rights for the publications made accessible in the public portal are retained by the authors and/or other copyright owners and it is a condition of accessing publications that users recognise and abide by the legal requirements associated with these rights.

- Users may download and print one copy of any publication from the public portal for the purpose of private study or research.

- You may not further distribute the material or use it for any profit-making activity or commercial gain

- You may freely distribute the URL identifying the publication in the public portal

If you believe that this document breaches copyright please contact us providing details, and we will remove access to the work immediately and investigate your claim 


\title{
Analytical miniaturization and nanotechnologies
}

\author{
Arben Merkoçi ${ }^{a}$ and Jörg P. Kutter ${ }^{b}$
}

DOI: $10.1039 / \mathrm{c} 2 \mathrm{lc} 90040 \mathrm{~h}$

This themed issue of Lab on a Chip is focused around the "III International Workshop on Analytical Miniaturization and NANOtechnologies (WAMNANO2012)", to be hosted in Barcelona (Spain) on June 11th and 12th, 2012. It covers the latest international developments on the use of nanotechnologies and nanomaterials for the design and applications of lab-on-a-chip (LOCs) and other miniaturized analytical (bio) systems. Nanotechnology is currently one of the most fascinating and challenging fields of

${ }^{a}$ Nanobioelectronics \& Biosensors Group, Catalan Institute of Nanotechnology, ICREA, Campus UAB, 08193, Bellaterra (Barcelona), Spain.E-mail: arben.merkoci@icn.cat

${ }^{b}$ Technical University of Denmark, Dept of Micro and Nanotechnology, Ørsteds Plads, Build. 345 east, 2800 Lyngby, Denmark. research and development. It is highly multidisciplinary, involving research from all scientific and engineering disciplines and as such is bringing significant support to analytical miniaturization. Nanotechnology provides great opportunities for innovation through the converging of knowledge in materials, photonics, electronics, biology and medicine, with technology-driven and applicationdriven approaches with interest for analytical applications. This themed issue showcases several important achievements in analytical miniaturization developments where nanotechnology is poised to bring advances in current knowledge.

The major focus of this issue is on clinical analysis in which nanotechnology enables novel devices and systems with an improved analytical performance.
Lechuga et al., (DOI: 10.1039/ C2LC40054E) show their last achievements in their LOC platform with 'onchip' detection using a bimodal waveguide (BiMW) interferometer. This platform achieves sensitive, label-free and real time biosensing with special interest for point of care diagnostics. Also working with optical detection but using two-dimensional photonic crystals (2D-PC) fabricated by nano-imprint lithography (NIL), Endo et al. (DOI: 10.1039/C2LC40066A) could detect insulin in a label-free mode through measurements of the refractive index changes caused by specific interactions between the antigen and an antibody. Electrochemical methods also are offering various opportunities for LOC applications. The contribution of nanomaterials such as carbon nanotubes (CNT) has

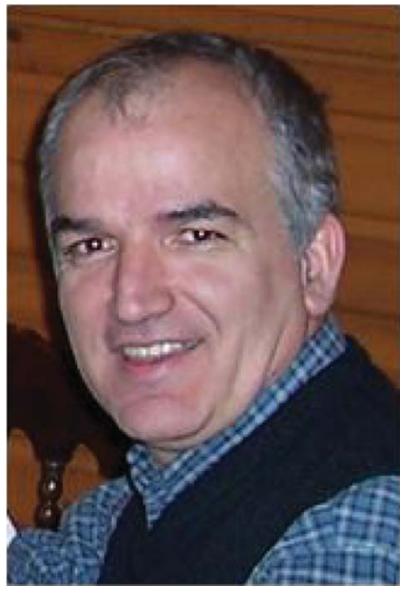

Arben Merkoçi
Prof. Arben Merkoçi is head of the Nanobioelectronics \& Biosensors Group at ICN (Institut Català de Nanotecnologia) in Barcelona. His research is focused on the integration of biological molecules (DNA, antibodies, cells, and enzymes) and other receptors with micro- and nanostructures as they apply to the design of novel sensors and biosensors. He is the author of over 150 manuscripts, special journal issues, and books on nanomaterials and biosensors and also serves as an Editor of the Nanoscience and Nanotechnology Encyclopedic Series launched by John Wiley \& Sons.

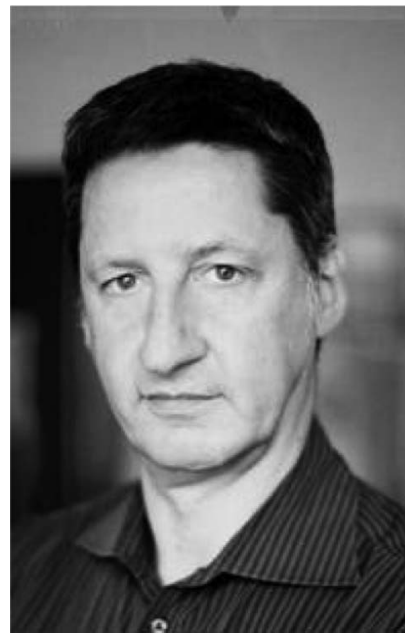

Jörg P. Kutter
Prof. Jörg P. Kutter received his B.S in Chemistry in 1991 and his $\mathrm{PhD}$ in Analytical Chemistry in 1995, both from the University of Ulm, Germany. After graduation, he became a postdoctoral research fellow at Oak Ridge National Laboratory (Oak Ridge, TN, USA) developing microchip-based analytical tools. In June 1998, he joined the Department of Micro and Nanotechnology of the Technical University of Denmark (DTU) in Lyngby, Denmark. In 2006, he was appointed professor in experimental lab-on-a-chip systems at DTU. He is group leader of the ChemLabChip Group focusing on the development of microfluidic devices for applications in life sciences. 
been one of the main focuses of the research in this field. By using a CNT/ PDMS based device with electrochemical detection, Carrilho et al. (DOI: 10.1039/ C2LC40141J) could detect serotonin at a detection limit of $0.2 \mathrm{nmol} \mathrm{L}{ }^{-1}$. Focusing on diagnostics, but applying a biosensor that integrates contactless conductivity transduction and folic acid as bioreceptors, the same group reports (DOI: 10.1039/ C2LC40157F) the sensitive detection of an FR- $\alpha$ cancer biomarker. As demonstrated by Delamarche et al. (DOI: 10.1039/ c2lc00015f), capillary driven microfluidics are simple to use. These platforms provide new opportunities to perform fast biological assays with nanogram quantities of reagents and microliters of samples. In this context, the authors describe the use of capillary soft valves (CSVs) as a simple-toimplement and actuate approach for stopping liquids in capillary-driven microfluidics. They illustrate the operation of these valves during the detection of DNA.

Quantum dots (QD) are also being investigated as interesting essential elements for various bioanalytical applications including those performed within microfluidics platforms. In addition, microfluidic platforms can be used for in situ synthesis of QDs. For this purpose, Alonso et al. (DOI: 10.1039/ C2LC00011C) report a green tape based microfluidics system that achieves in-chip CdSe QD synthesis at controlled high temperature. Their approach promises an interesting cost-efficient alternative for nanocrystals synthesis in organic media. Besides in-chip synthesis, in-chip QD detection is very interesting considering the various bioanalytical applications where QDs can be used as labels for DNA, proteins and even cells. The electrochemical properties of QDs can easily be evaluated using an in-chip integrated electrochemical system. Merkoçi et al. (DOI: 10.1039/ C2LC00007E) have designed a flexible hybrid polydimethylsiloxane (PDMS)/ polycarbonate (PC) microfluidic chip with integrated screen-printed electrodes (SPE) to detect CdS QDs. In addition to the in-chip CdS detection, a recirculation system with the aim of achieving lower detection limits using reduced volumes of sample is also proposed.

An interesting application of lab-on-achip systems concerns their use as platforms for active transport through nanomachines. Wang (DOI: 10.1039/ c2lc00003b) reviews the latest achievements by his and other groups in the field concerning the use of nanomotors for cargo manipulations and the development of miniaturised LOCs to drive transport processes along microchannel networks. Focusing on cargo-lifting within a LOC platform, Kuhn et al. (DOI: 10.1039/c2lc21301j) report an interesting approach for a simple fuelfree vertical propulsion of conducting beads in liquid filled capillaries based on bipolar electrochemistry. The developed cargo-lifting approach might also be used in the design of miniaturized microchannel viscosimeters, valves and pumps.

Recent advances in ultra-compact, rolled-up components as parts of lab-ina-tube total analysis system are reviewed by Schmidt et al. (DOI: 10.1039/ c2lc21175k). The authors give an overview of the advantages that the system brings to biosensing including the optical, electrical and magnetic components related to detection. According to the authors, "the lab-in-a-tube offers a great opportunity in both reducing the size of lab-on-chip systems as well as allowing for a large number of data points taken from individual organisms under similar growth conditions".

General aspects related to the use of nanomaterials in lab-on-a-chip technologies have been reviewed by Merkoçi et al. (DOI: 10.1039/C2LC40063D). The authors show recent trends in the integration of nanomaterials into LOC and the advantages in relation to system sensitivity and miniaturization. They also cover aspects such as the use of nanomaterials in building or modifying optical and electrochemical detectors, improving sample pre-treatment or separation processes, besides discussing the use of LOCs as platforms for nanomaterials synthesis, toxicology and drug delivery related studies. Aspects related to the use of carbon nanotubes for electrochemical sensing in microfluidic chips are carefully considered by Escarpa et al. (DOI: 10.1039/C2LC40099E). The single wall carbon nanotubes (SWCNT) were characterized by near infrared (NIR) spectroscopy yielding the Purity Index (NIR-PI) as an important analytical parameter to be considered prior to their application in electrochemical sensing. Mogensen and Kutter (DOI: 10.1039/C2LC40102A) also review the state of the art on the use of CNTs and other related carbon nanomaterials, such as graphene, in microchip chromatography. The authors give a critical overview of the various strategies used to implement these nanomaterials for microfluidic chromatography devices in terms of separation efficiency and fabrication strategies.

We really hope that the readers will enjoy these high-calibre contributions in this special issue, showcasing the many facets of using nanotechnology in the context of lab-on-a-chip devices.

\section{Acknowledgements}

A.M thanks the support given by MICINN (Spain) (MAT2011-15249-E) for the organization of the WAM NANO 2012 in Barcelona. Both guest editors are grateful for support received by the E.U. under FP7 contract number 246513 "NADINE". 